"Mircea cel Batran" Naval Academy Scientific Bulletin, Volume XIX - 2016 - Issue 2

The journal is indexed in: PROQUEST / DOAJ / Crossref / EBSCOhost / INDEX COPERNICUS / DRJI / OAJI I

JOURNAL INDEX I I2OR / SCIENCE LIBRARY INDEX / Google Scholar / Academic Keys/ ROAD Open Access I

Academic Resources / Scientific Indexing Services / SCIPIO / JIFACTOR

\title{
DEFECT IDENTIFICATION OF MOVING PARTS OF A MECHANICAL INSTALLATION USING CORRELATION BETWEEN VIBRATION AND NOISE
}

\author{
Tiberiu PAZARA ${ }^{1}$ \\ Mihail PRICOP ${ }^{2}$ \\ Ionut-Cristian SCURTU ${ }^{3}$ \\ Codruta PRICOP ${ }^{4}$ \\ Ovidiu RADU ${ }^{5}$ \\ ${ }^{1}$ Lecturer dr.eng., Naval Academy, Constanta \\ ${ }^{2}$ Captain(N) Associate Professor dr.eng., Naval Academy, Constanta \\ ${ }^{3}$ Ltjg(N) instr.eng., Naval Academy, Constanta \\ ${ }^{4}$ Associate Professor dr.eng., Maritime University, Constanta \\ ${ }^{5}$ Captain (N) dr.eng., Research Center for Navy, Constanta
}

Abstract:Cracks due to fatigue or imperfections from manufacturing are common defects for the moving parts of an installation. In this paper, the authors measure the vibrations and noise of a scale model to determine the defects of bearings and other moving parts. Usually, these defects are identified by means of vibration analysis. Here, the authors use noise analysis and correlation between noise and vibration to locate the faults. Finally, conclusions are made regarding which method is more efficient.

Keywords:defect, vibration, noise, correlation

\section{Introduction}

Defect identification is a constant preoccupation for engineers in order to prevent the partial or total damage of an equipment. Defects occur due to fatigue, manufacturing problems, assembling problems and improper operation of equipment. The most used technique to identify defects is vibration measurement because it can detect even smaller cracks and wears without dissembling the installation and without performing visual inspection under microscope.

Fatigue of mechanical installations, electrical installations can also be identified using noise measurements. Sometimes, the defects can be heard, but that happens for high values of rotational speed of the installation's moving parts. The use of correlation between vibrations and noise in defect estimation is a tool that can confirm the presence of fatigue. In this paper, it is investigated the possibility of identifying a bearing defect using correlation. The correlation between two signals is expressed with thefunction „coherence“:

$$
\gamma^{2}=\frac{\left|W_{X Y}\right|^{2}}{W_{X X} \cdot W_{Y Y}}
$$

where $W_{X Y}$ is the cross spectrum, $W_{X X}$ is the power spectrum of signal $X, W_{Y Y}$ is the power spectrum of signal $\mathrm{Y}$.

The values of coherence function $\gamma^{2}(f)$ are between 0 and 1 , where 0 means the signals are independent and 1 means the signals are equal.This analysis function can tell the corresponding degree between two signals, meaning how much a signal can be found in another signal $[1,2]$.

\section{The experiment}

To simulate the defect of a bearing, it was used an experimental stand with an electrical motor and a shaft which set in motion a belt rolling over two bearings. The revolution speed of the motor is controlled so that the simulations were conducted at various speeds. The stand permit the simulation of outer ring defect, inner ring defect, ball defect, cage defect and belt defect.

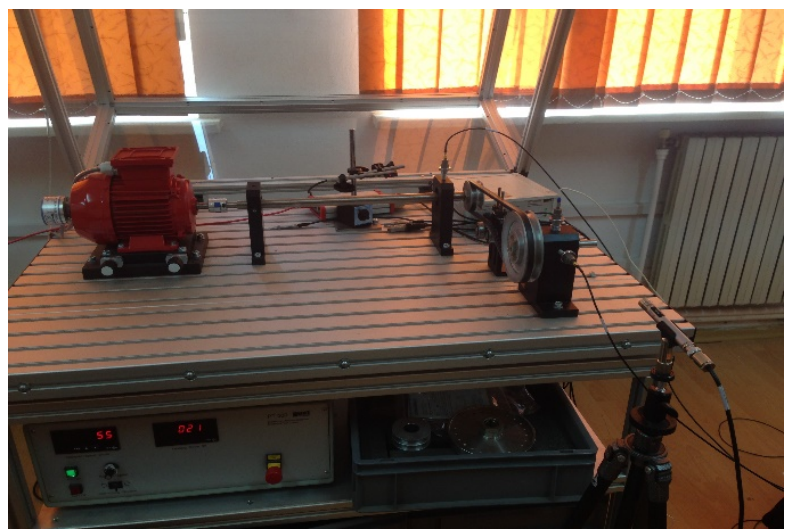

Fig.1 - Experimental stand

The measurement chain contains a data acquisition system and a laptop, all integrated in a box - Machine Diagnostic Toolbox 9727 from Bruel\&Kjaer. To measure the vibrations, 3 uniaxial accelerometers type 752A12 (B\&K) were mounted

(c) 2015. This work is licensed under the Creative Commons Attribution-Noncommercial-Share Alike 4.0 License. 
"Mircea cel Batran" Naval Academy Scientific Bulletin, Volume XIX - 2016 - Issue 2 The journal is indexed in: PROQUEST / DOAJ / Crossref / EBSCOhost / INDEX COPERNICUS / DRJI / OAJI / JOURNAL INDEX / I2OR / SCIENCE LIBRARY INDEX / Google Scholar / Academic Keys/ ROAD Open Access I Academic Resources / Scientific Indexing Services / SCIPIO I JIFACTOR

and for noise it was used a microphone type 4189A21 (B\&K).

The motor speed was set to three RPM's, 500 RPM $(8,33 \mathrm{~Hz}), 1500$ RPM $(25 \mathrm{~Hz})$ and 2500 RPM $(41,66 \mathrm{~Hz})$.

A bearing with outer ring defect was used for the measurements. The bearing is typeNU204-ETVP2 (now renamed as NU204-E-XL-TVP2)and it has the following characteristics: inside diameter - 20mm, outside diameter - 47mm, width $14 \mathrm{~mm}$, number of balls/rollers $=12$. The position of the bearing is at the end of shaft, which is position 1 in figure 2.

Each measurement was recorded for a 30 s time period. Vibrations and noise were measured and recorded simultaneously. Two accelerometers were mounted to measure vertical vibrations, and one accelerometer was mounted to measure longitudinal vibrations. The microphone was placed at $1,2 \mathrm{~m}$ from the ground and at $1 \mathrm{~m}$ from the experimental stand.

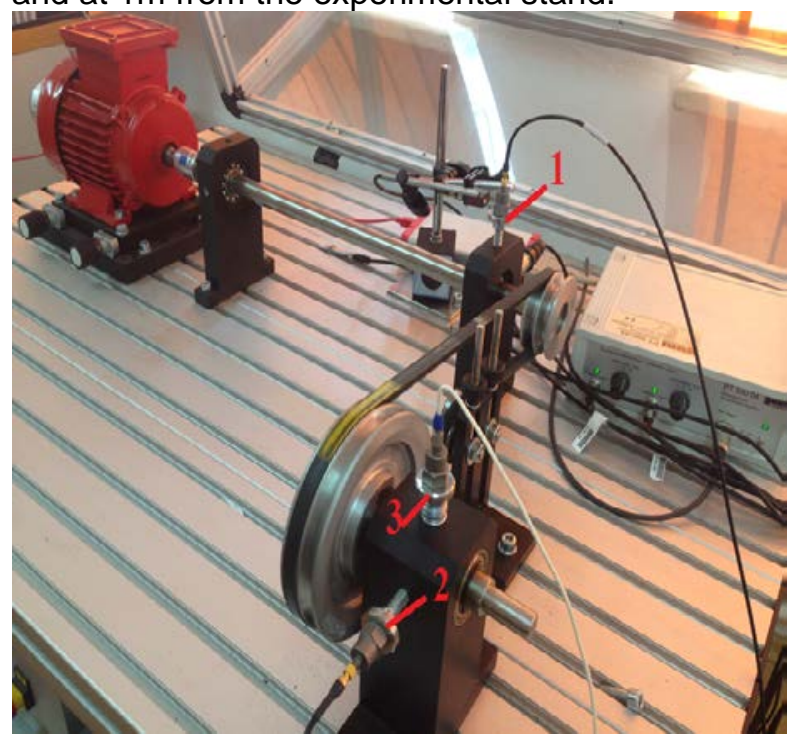

Fig. 2 - Positions of accelerometers

(1 - acc. mounted on joint between shaft and belt;

2 - acc. mounted longitudinal on bearing cage;

3 - acc. mounted vertical on bearing cage)

\section{Measurement analysis}

The signals from accelerometers and microphone were recorded on the hard drive of the laptop which allows the post-analysis at any time. The software used in analysis was PULSE LabShop. The setup of the software is presented in figure 3 : frequency span - $800 \mathrm{~Hz}$; nr. of lines - 1600; resolution $-0,5 \mathrm{~Hz}$.

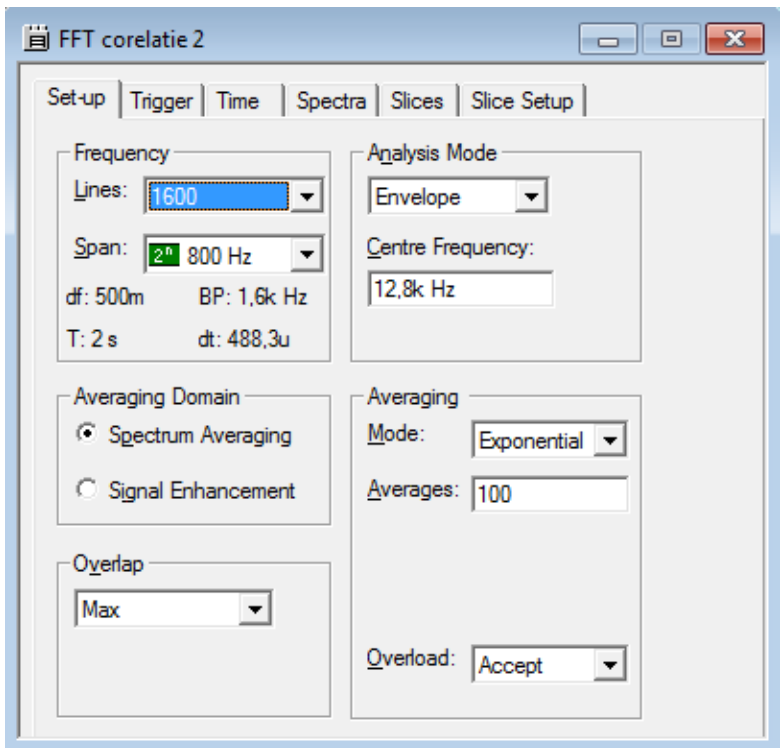

Fig.3 - setup of PULSE

Usually, the bearing faults are analyzed using the FFT function. Thesedefects have an amplitude modulating effect. To identify the faults, the modulating signal is extracted from the amplitudemodulated signal. The obtained signal can be studied in time domain or frequency domain. This technique is called Envelope Analysis and is used especially for defects detection in bearings, gearboxes, turbines, induction motors etc. [3], [4], [5], [6], [7], [8], [9].Besides the usual FFT function, the signals were analyzed using the Coherence function for the same frequency span 0-800 $\mathrm{Hz}$.

Motor frequency and shaft frequency are the same and are calculated in simple manner:

$$
f_{\text {motor } / \text { shaft }}=\frac{\text { motor } R P M}{60}
$$

Outer ring defect frequency of the bearing (BPFO) is calculated using the following equation:

$$
f_{B P F O}=\frac{n}{2} f_{\text {motor/shaft }}\left(1-\frac{B D}{P D} \cos \beta\right)
$$

$\mathrm{n}$ - number of balls or rollers

$\mathrm{BD}$ - ball diameter

PD - pitch diameter

$\beta$ - contact angle

The frequencies calculated based on exact RPM of the motor (500 RPM, 1500 RPM2500 RPM) are presented in table 1 . The motor RPM is assumed to be exact, although the controlling knob isn't precise. The real values are presented in table 2. 
"Mircea cel Batran" Naval Academy Scientific Bulletin, Volume XIX - 2016 - Issue 2 The journal is indexed in: PROQUEST / DOAJ / Crossref / EBSCOhost / INDEX COPERNICUS / DRJI / OAJI I JOURNAL INDEX I I2OR / SCIENCE LIBRARY INDEX / Google Scholar / Academic Keys/ ROAD Open Access I Academic Resources / Scientific Indexing Services / SCIPIO / JIFACTOR

Table1

\begin{tabular}{|l|c|c|c|c|}
\hline & \multicolumn{4}{|c|}{ FREQUENCY } \\
\hline & Fundamental & $1^{\text {st }}$ order & $\begin{array}{c}2^{\text {nd }} \\
\text { order }\end{array}$ & $3^{\text {rd }}$ order \\
\hline 500 RPM & \multicolumn{4}{|c|}{} \\
\hline Motor/shaft & 8,33 & 16,66 & 24,99 & 33,32 \\
\hline BPFO & 29.8 & 59,6 & 89,4 & 119,2 \\
\hline 1500 RPM & 25 & 50 & 75 & 100 \\
\hline Motor/shaft & 90 & 180 & 270 & 360 \\
\hline BPFO & 41,66 & 83,32 & 124,98 & 166,64 \\
\hline 2500 RPM & 149.1 & 298,2 & 447,3 & 596,4 \\
\hline Motor/shaft & \multicolumn{5}{|l}{} \\
\hline BPFO & \multicolumn{5}{|l|}{} \\
\hline
\end{tabular}

Part of FFT analysis is presented in the next 3 figures where it can be seen the spectra of vertical vibrations measured with accelerometer 1.

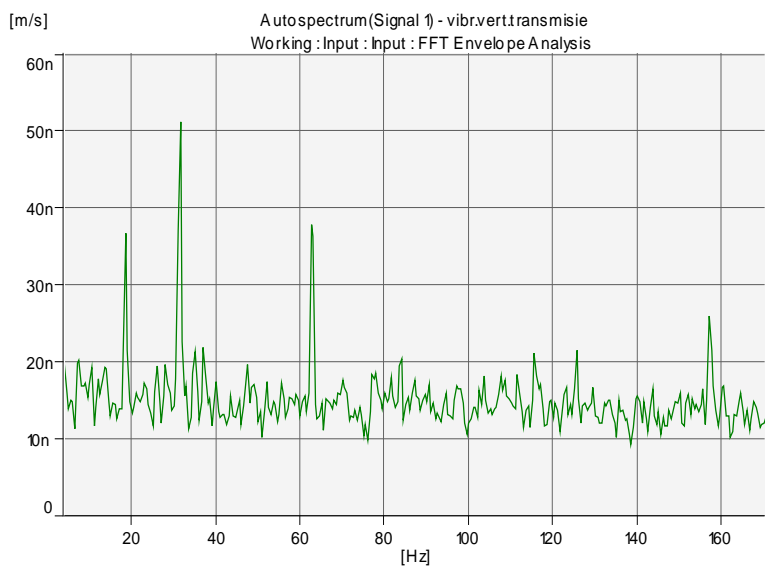

Fig.4 - FFT analysis of vertical vibrations (acc.1), 500RPM

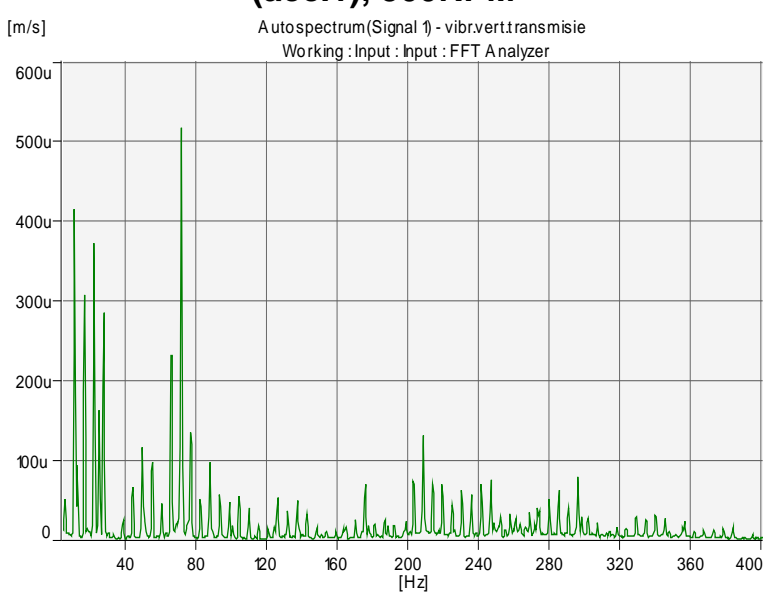

Fig.5 - FFT analysis of vertical vibrations (acc.1), 1500RPM

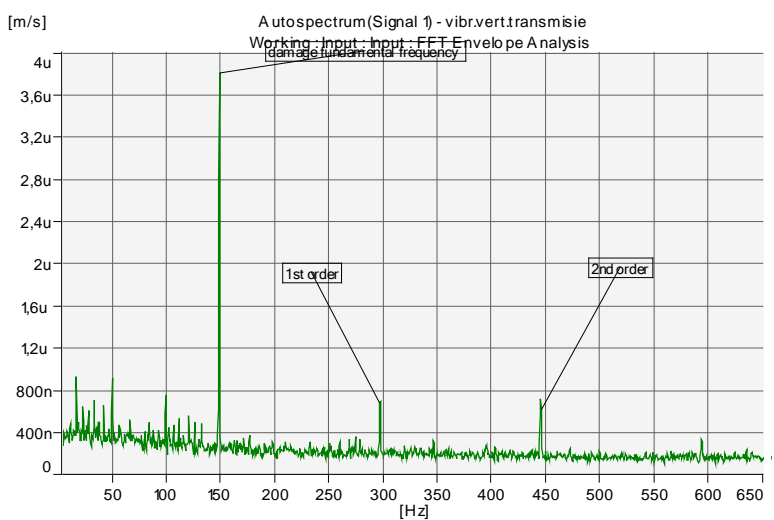

Fig.6 - FFT analysis of vertical vibrations (acc.1), 2500RPM

The coherence between vibrations and noise is presented in figures 7 through 15 . Each figure is related to measurement positions of accelerometers and rotational speed of motor.

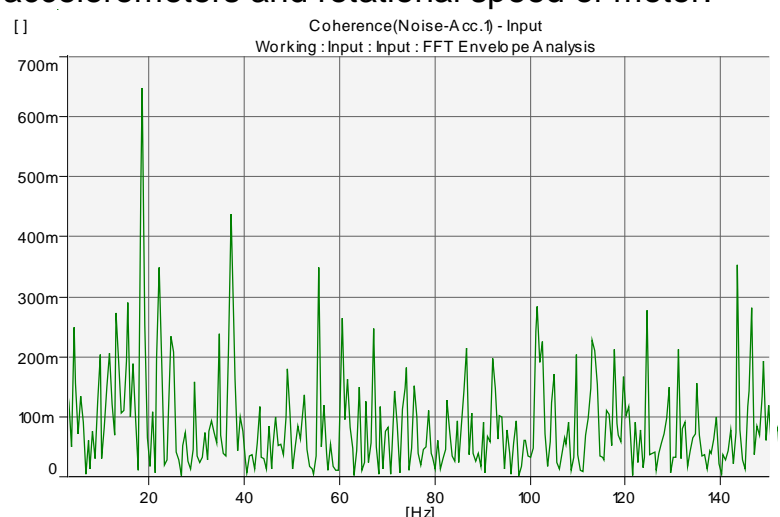

Fig.7 - Coherence between vertical vibrations (acc.1) - noise, 500RPM

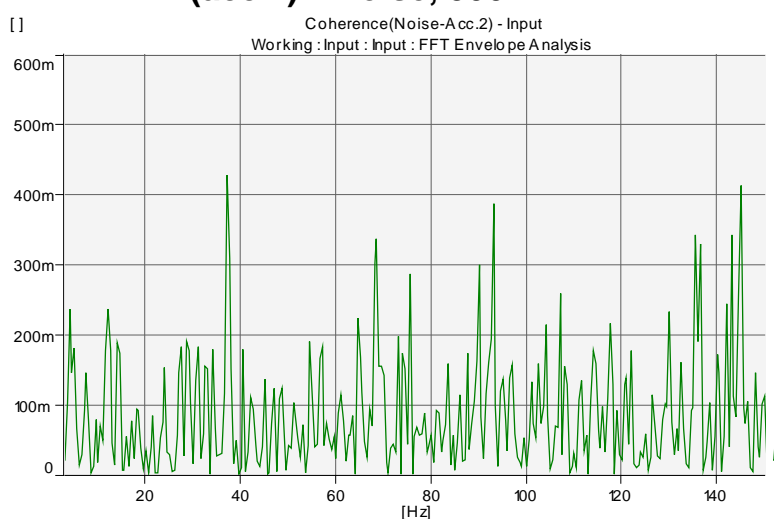

Fig.8 - Coherence between longitudinal vibrations (acc.2) - noise, 500RPM 
"Mircea cel Batran" Naval Academy Scientific Bulletin, Volume XIX - 2016 - Issue 2 The journal is indexed in: PROQUEST I DOAJ / Crossref / EBSCOhost / INDEX COPERNICUS / DRJI / OAJI I JOURNAL INDEX / I2OR / SCIENCE LIBRARY INDEX / Google Scholar / Academic Keys/ ROAD Open Access I Academic Resources / Scientific Indexing Services / SCIPIO / JIFACTOR

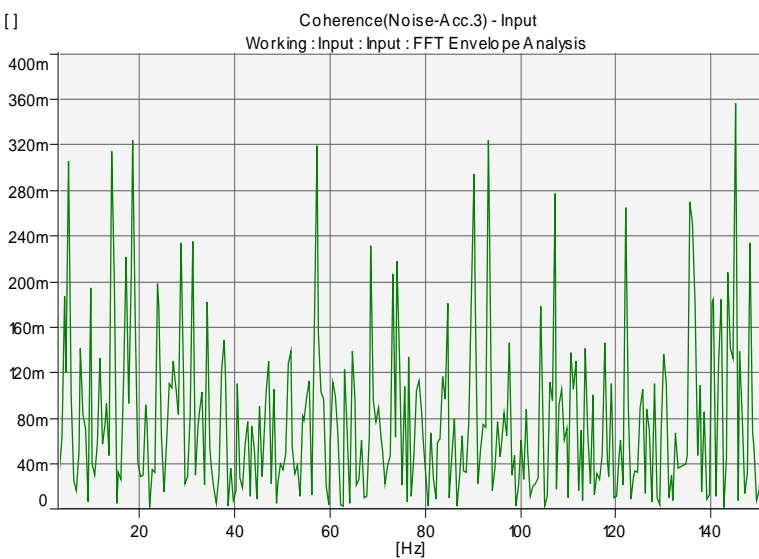

Fig.9 - Coherence between vertical vibrations (acc.3) - noise, 500RPM

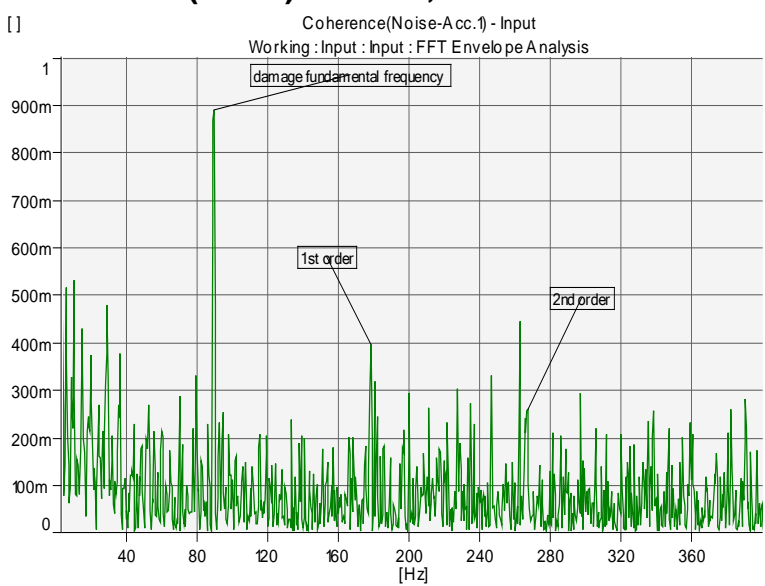

Fig.10 - Coherence between vertical vibrations (acc.1) - noise, 1500RPM

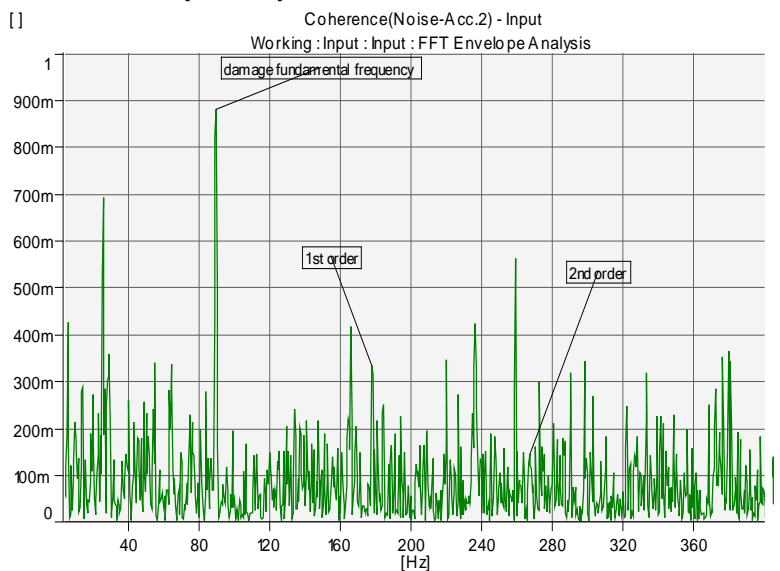

Fig.11 - Coherence between longitudinal vibrations (acc.2) - noise, 1500RPM

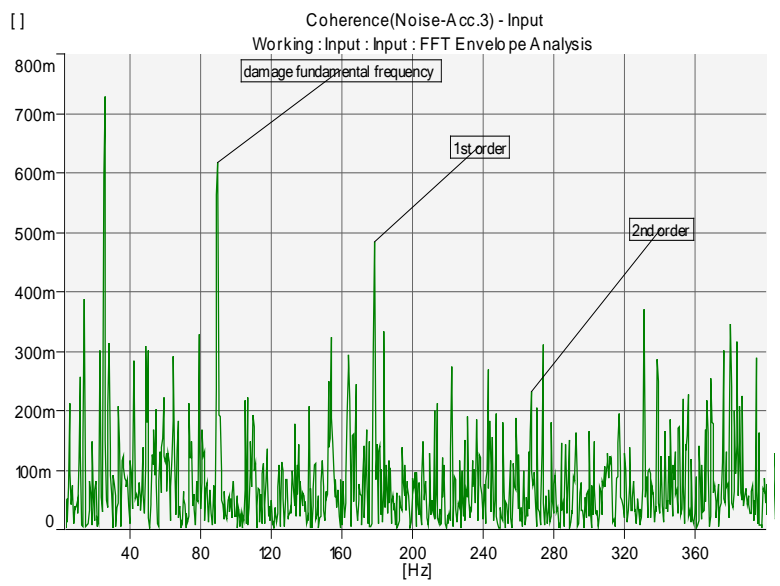

Fig.12 - Coherence between vertical vibrations (acc.3) - noise, 1500RPM

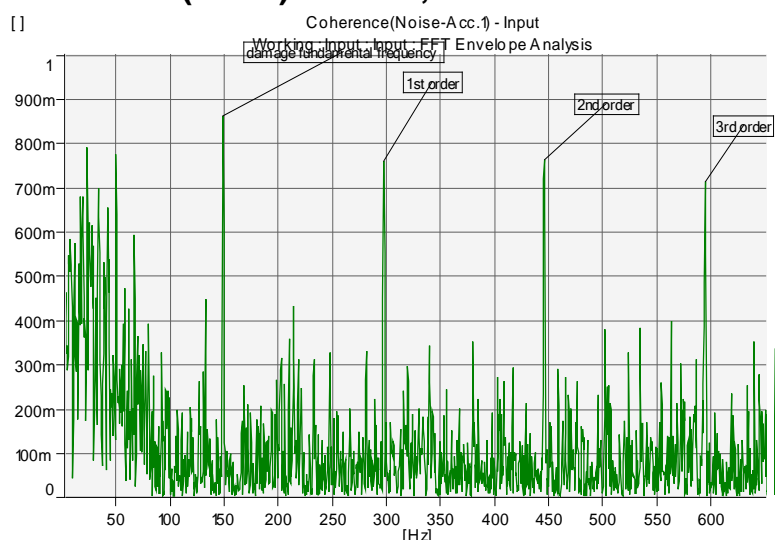

Fig.13 - Coherence between vertical vibrations (acc.1) - noise, 2500RPM
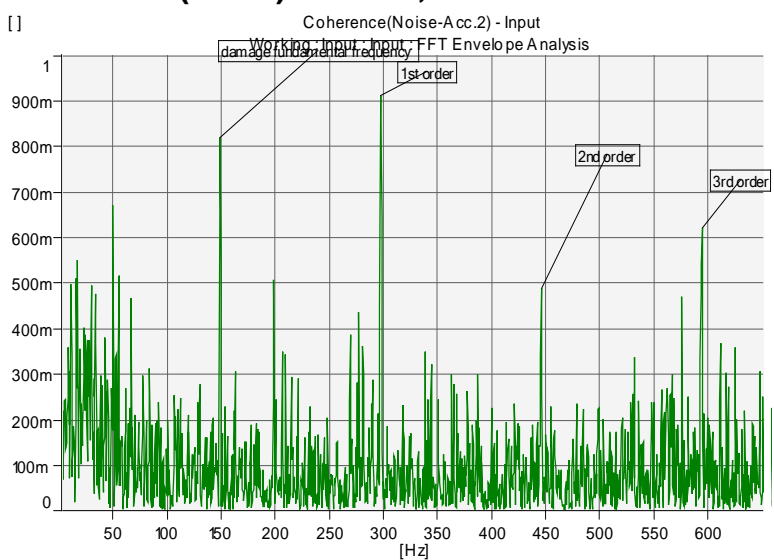

Fig.14 - Coherence between longitudinal vibrations (acc.2) - noise, 2500RPM 


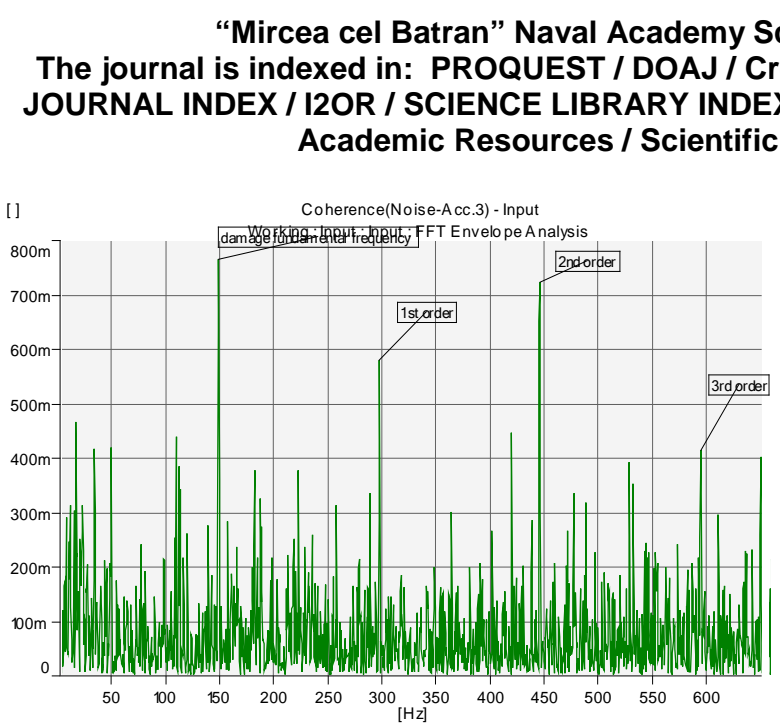

Fig.15 - Coherence between vertical vibrations (acc.3) - noise, 2500RPM

4. Interpretation of the results

Frequencies obtained from FFT analysis are presented in table 2 .

Table 2

\begin{tabular}{|l|c|c|c|c|}
\hline & \multicolumn{4}{|c|}{ FREQUENCY } \\
\hline & Fundamental & $\begin{array}{c}1^{\text {st }} \\
\text { order }\end{array}$ & $\begin{array}{c}2^{\text {nd }} \\
\text { order }\end{array}$ & $\begin{array}{c}3^{\text {rd }} \\
\text { order }\end{array}$ \\
\hline 500 RPM & \multicolumn{5}{|c|}{} \\
\hline Motor/shaft & 8,78 & 17,56 & 26,34 & 35,12 \\
\hline BPFO & 31,5 & 63 & 94,5 & 126 \\
\hline 1500 RPM & 25 & 50 & 75 & 100 \\
\hline Motor/shaft & 89 & 178 & 267 & 356 \\
\hline BPFO & \multicolumn{5}{|l}{} \\
\hline
\end{tabular}

\begin{tabular}{|l|c|c|c|c|}
\hline 2500 RPM & \multicolumn{4}{|c|}{} \\
\hline Motor/shaft & 41,38 & 82,76 & 124,14 & 165,52 \\
\hline BPFO & 148,5 & 297 & 446,5 & 594 \\
\hline
\end{tabular}

Analyzing the coherence spectra, a first observation can be made: for low RPM there are numerous peaks which are not related to bearing defect; for higher RPM, the coherence has very good values at the frequencies of the damage.

The differences between the results for low RPM and high RPM are explained due to fact that in the noise spectra at low frequencies the dominant frequencies are the ones of the motor and shaft and their harmonics. Also, at low frequencies, damages can't be heard or can't be distinguished from the other sources.

When the motor is set to 1500 RPM, in the coherence spectra the fundamental frequency of the defect can be see clearly, but the harmonics have low values (figures 10, 11, 12). With the increase of motor's speed to 2500 RPM, defect frequencies dominate the coherence spectra (figures 13, 14, 15).

Coherence has good and very good values for fundamental frequency at 1500 and 2500 RPM. Coherence amplitude of harmonics increase with the increase of RPM.

\section{CONCLUSIONS}

It is important to notice that the results confirm what was expected, meaning that a bearing damage can be detected in the noise spectra. Here, the tool used to investigate the defects was coherence between vibration and noise. For a slow motor speed, it is expected that the noise created by the damage can't be heard. But with the increase of RPM, the bearing damage can be heard, especially the harmonics.

The measurements made at $500 \mathrm{~Hz}$ present a spectra where the defect can't be distinguished clearly. Both noise and vibrations created by the damage of the outer ring of the bearing are masked by the motion of the moving parts of the system (figures $7,8,9$ ).

When the RPM of the motor increase the Coherence peaks associated with the defect become visible. The higher the frequency, the bigger the peaks figures 10...15). Also the noise produced by the defect can be sensed at higher frequencies.

Regarding the measuring positions of the accelerometers, there is no influence over the correlation between noise and vibrations.

Coherence presents the highest value at fundamental frequency of the defect, and decreasing values at harmonics of $1^{\text {st }}$ and $2^{\text {nd }}$ order.

The coherence between noise and vibrations confirm the existence of a defect. But a conclusion regarding the severity of the defect cannot be drawn. A value closer to 1 for Coherence doesn't mean that the damage is severe.

In conclusion, the use of correlation between noise and vibrations to investigate damages can be successfully applied for high rotational frequencies.

\section{BIBLIOGRAPHY}

[1] Enescu N., Magheți I., Sârbu M.A.: Acustica Tehnică, Editura ICPE, București, 1998

[2] Magheți I., Savu M.: Vibrații mecanice. Teorie și practică, Editura BREN, București, 2004

[3] Konstantin-Hansen $\mathrm{H}$., Herlufsen $\mathrm{H}$.: Envelope and Cepstrum Analysis for Machinery Fault Identification, Sound \& Vibration, May 2010, http://www.sandv.com/downloads/1005hans.pdf

[4] ${ }^{* \star \star}$ Rolling Element Bearings - Condition Monitoring, Vibration Matters, Series 3, Issue 3, January 2016

(c) 2015. This work is licensed under the Creative Commons Attribution-Noncommercial-Share Alike 4.0 License. 
"Mircea cel Batran" Naval Academy Scientific Bulletin, Volume XIX - 2016 - Issue 2 The journal is indexed in: PROQUEST / DOAJ / Crossref / EBSCOhost / INDEX COPERNICUS / DRJI / OAJI / JOURNAL INDEX I I2OR / SCIENCE LIBRARY INDEX / Google Scholar / Academic Keys/ ROAD Open Access I Academic Resources / Scientific Indexing Services / SCIPIO / JIFACTOR

[5] *** Rolling Element Bearings - Condition Monitoring, part 2, Vibration Matters, Series 3, Issue 4, April 2016

[6] ${ }^{* \star \star}$ Rolling Element Bearings: Vibration; the complete picture, Vibration Matters, Series 3, Issue 5, June 2016

[7] ${ }^{\star \star \star}$ Rolling Element Bearings: Stages of Faults, Vibration Matters, Series 3, Issue 6, July 2016

[8] ${ }^{\star \star \star}$ Rolling Element Bearings: Stages of Faults; \#3, Vibration Matters, Series 3, Issue 7, August 2016

[9] ${ }^{* * *}$ Rolling Element Bearings: Stages of Faults; \#4, Vibration Matters, Series 3, Issue 8, September 2016 